\title{
Antegrade elastic stable intramedullary nailing in treatment of irreducible distal radius fractures in diaphyseal-metaphyseal junction in children
}

\section{Weifeng Lin}

Wuxi Hand Surgery Hospital

Shuai Liu ( q qkxydx@alumni.hust.edu.cn )

Wuxi Hand Surgery Hospital https://orcid.org/0000-0003-3104-5319

Taotao Hui

Wuxi Hand Surgery Hospital

Research article

Keywords: Elastic stable intramedullary nailing, Internal fixation, Children, Radius fracture

Posted Date: March 20th, 2020

DOI: https://doi.org/10.21203/rs.3.rs-18142/v1

License: (1) This work is licensed under a Creative Commons Attribution 4.0 International License.

Read Full License 


\section{Abstract}

\section{Purpose}

This paper aimed to study the method and outcome of antegrade elastic stable intramedullary nailing (ESIN) for irreducible distal radius fractures in diaphyseal-metaphyseal junction in children.

\section{Methods}

27 irreducible distal radius fractures in children ranging in age from six to 13 years treated with closed reduction and antegrade ESIN from March 2017 to September 2018 were analyzed retrospectively. The series comprised 24 boys and three girls. 17 cases were double fractures in forearms and ten cases were single fractures of radius. Each case was treated with closed reduction, internal fixation of antegrade ESIN and plaster cast. ESIN was removed when fracture healed and remodelled well. Cooney modified Green-O'Brien wrist score was used to evaluate the wrist function. Ranges of motion (ROM) in bilateral wrists were contrasted at the final follow-up. $\mathrm{P}<0.05$ was considered statistically significant in the difference.

Results

All the fractures healed four to six weeks post-operative. At the final follow-up (12-16 months), there was no statistical significance in ROM of bilateral wrists (all $p>0.05$ ). The mean Cooney modified GreenO'Brien wrist score was 93 (80-100) including 25 excellent (93\%) and two good (7\%) results.

\section{Conclusions}

The technique of antegrade ESIN is effective and minimal invasive for irreducible distal radius fractures in children. The criterion of proximal radius approach to implant ESIN should be studied further in minimal invasive therapy of fractures.

\section{Introduction}

Distal radius fracture is common in children. Generally we mean this fracture as the segment locates in the junction of diaphyseal-metaphyseal of radius[1] (Fig.1). It occurred usually when elbow extending, forearm pronating and wrist extending by indirect violence. The incidence of which is increasing gradually as potential pattern changes of physical activity and poor calcium intake[1, 2]. Closed reduction with plaster cast fixation is the first choice for most cases. But the rate of re-displacement of fractures is up to $39 \%[3]$ due to the interaction of muscles and interosseous membrane in forearm. Various techniques are applied for this fracture presently including crossed K-wires[4], opened reduction and fixation with plate and screws, and prebending elastic stable intramedullary nailing (ESIN)[1] if closed reduction failed or the reduction could not be sustained with cast fixation. Each technique above has its own advantages and disadvantages. More skilled procedure would be chosen by surgeon empirically. In 
our institution, antegrade ESIN was chosen by which satisfactory reduction and fixation of irreducible distal radius fracture were achieved. This procedure is introduced below.

\section{Materials And Methods}

\section{General information}

27 pediatric cases with irreducible distal radius fractures from March 2017 to September 2018 were studied retrospectively after the approval (LW 2020002) from the ethical committee of our institution was acquired. The series comprised 24 boys and three girls. 17 cases were double fractures in forearms and ten cases were single fractures of radius. 12 cases were involved in left side and 15 cases in right side. The average age was ten years (range six to 13 years). Each case was treated with closed reduction, internal fixation of antegrade ESIN and plaster cast.

Cases in this study should meet all the inclusion criteria: (1) their ages were between six to 14 years and their weights were less than $50 \mathrm{~kg}$; (2) radius fractures were closed accompanied with ulnar fractures or not; (3) two-part fractures; (4) failed to closed reduction or the reduction could not be sustained with longarm cast; (5) residual angle of broken ends $>10^{\circ}$ in coronal plane or the shortening $>0.5 \mathrm{~cm}$. The exclusion criteria was followed: (1) age < six years with more successful closed reduction; (2) weight $\geq$ $50 \mathrm{~kg}$ with stronger tension of muscles and soft tissues for which reduction was difficult to sustain by ESIN; (3) open fracture or skin upon the site to implant ESIN injured; (4) multiple or comminuted fractures; (5) no displacement or angle of broken ends $\leq 10^{\circ}$ in coronal plane; (6) successful in closed reduction and no re-displacement or re-angulation after cast fixation; (7) accompanied with injury of nerve or vessel; (8) physis involved; (9) pathological fractures.

\section{Operative procedures (Fig.3)}

(1) Diameter of the narrowest site of bone was measured in radiogram pre-operative and ESIN was selected according to $60 \%-80 \%$ of the diameter. (2) Prebended ESIN about $30^{\circ}$ at the site $3 \mathrm{~cm}$ to $4 \mathrm{~cm}$ away from the nail tip for implanting easily. (3) The child was in supine position with the involved limb in abduction, basal plus brachial plexus anesthesia were then adopted. (4) The ulnar fracture should be reduced and fixed firstly with ESIN through olecroanon if existed. (5) Sustained the forearm in neutrality and elbow in flexion about $90^{\circ}$. Located the superior $1 / 3$ point between lateral epicondyle of humerus and radial styloid process on the skin surface. Translated the point palmarly about $1 \mathrm{~cm}$ and made an incision for about 1.5-2.0cm (Fig.2). (6) The interval between brachioradialis and extensor carpi radialis longus was dissected deeply. Then rotated the forearm to supination and separated the space between supinator and flexor digitorum superficialis. Exposed the cortex of proximal radius by dissecting the tendinous tissues bluntly. (7) Drilled the cortex for about $45^{\circ}$ along with the bone surface and implanted prebended ESIN to the broken end. Adjusted the nail tip towards the distal broken end (usually radially) under fluoroscopic guidance. (8) Manipulatively reduced radial fracture and fit the ends for at least 1/3. ESIN was then beat into the distal end by hammer rather than by handle for decreasing the accident injuries of extramedullary tissue. (9) Continued beating ESIN into the distal end approximately to the physis. 
Adjusted the nail tip towards the ulnar side to reduce the fracture ultimately. (10) The reduction was identified again under fluoroscopic guidance. Bended and cut off the nail tail at about $0.5 \mathrm{~cm}$ above the cortex. Closed the incision. Long-arm cast was then applied sustaining the forearm in neutrality and elbow in flexion.

\section{Follow-up and evaluation}

Children would leave hospital as limbs pain relieved for about three to four days post-operative usually. Radiograph was taken every two weeks. Union of fracture was considered if continuous osteotyluses crossing the broken ends were seen on the radiographs. Then removed the cast. ESIN was removed four

to eight months post-operative as the fracture healed and remodelled well. At the final follow-up, Cooney modified Green-0'Brien wrist score[5] was used to evaluate the wrist function. The function would be considered excellent (90-100), good (80-89), moderate (65-79) or poor $(<65)$. Considering that the strength of dominant hand may be higher than the nondominant, a ratio of $6 \%$ was added to the strength value of the nondominant hand[6].

\section{Statistical analysis}

SPSS 22.0 (SPSS, Chicago, IL, USA) was used to analyse the data collected. Paired Sample T test was applied to compare the ranges of motions (ROM) of involved and healthy wrists at the final follow-up. $\mathrm{P}<0.05$ was considered statistically significant in the difference.

\section{Results}

All fractures united four to six weeks post-operative. Comparisons of ROM of bilateral wrists were shown in table 1 (all $p>0.05$ ). Cooney modified Green and O'Brien scores were shown in table 2 . The mean score was 93 (80-100) including 25 excellent (93\%) and two good (7\%) results. No irritation of skin, infection of nail canal or injuries of tendon, nerve and vessel were seen in all cases.

\section{Discussion}

Distal radius fracture in diaphyseal-metaphyseal junction is unstable in rotation and is difficult to reduce and sustain due to the interaction among interosseous membrane of forearm, brachioradialis, pronator teres and quadratus. Johari et al.[7] found that distal ridial physis had nothing to do with the angulation deformity in coronal plane almost. Roberts[8] emphasized the influence of radial inclination of distal ridius to function was greater than angulation in sagittal plane. Radius rotates around ulna should be considered as motion of articulation for which rotation of forearm is as significant as extension-flexion. Morrey et al.[9] suggested in 1981 that it needed at least $100^{\circ}$ of rotation of forearm to complete most daily works. Today this lower limit of rotation should be improved higher. Other studies suggested it was an indication to operate that interosseous membrane of forearm compressed remarkablely for the 
restriction of rotation[8, 10]. Asadollahi et al.[11] found it easier to re-displace if the initial angulation of fracture was more than $10^{\circ}$ and no anatomical reduction achieved. Higher ratio of re-displacement is refered to closed reduction and cast fixation[12]. If cast index is oversized, this ratio would be greater[13]. The findings above reminded that angulation should be corrected completely in coronal plane and as far as possible in rotation. The residual angulation should be less than $10^{\circ}$ in sagittal plane. For these reasons, to achieve more precise reduction became a purpose of operation.

Open reduction and plate fixation was used before ESIN technique was available. This method which is more recommended for children whose skeletal maturity is within one year provides anatomical reduction and rigid fixation[14]. Early functional exercise could be given as long as the incision healed. However, the larger incision sometimes is the only consideration of parents. The strength of pronation may descend for the injury to pronator quadratus and open reduction may be the strongest risk factor of delayed union of forearm fracture in children for its damage to blood supply of broken ends[15]. For these reasons, indirect reduction was acquired with another method antegrade ESIN in our institution.

In this study, adequate motions of flexion-extension and inclination of wrists and rotation of forearms were acquired in all 27 cases. There was no statistically difference seen in the ROM of bilateral wrists. According to Cooney modified Green and O'Brien score, two cases (7\%) were evaluated as good for their "grip strength" in involved limbs were less than the healthy. Another reason was the ROM of bilateral wrists were not congruent completely. Considering that their dominant hands were not the same, more evaluating criterion such as score of disability of arm-shoulder-hand would be used for further assessment. Huang et al.[4] reported 48 cases of irreducible distal radius fracture treated with percutaneous joystick having acquired an excellent-rate of $91.7 \%(44 / 48)$ and a good-rate of $8.3 \%(4 / 48)$. Fisher's exact test was used to compared the difference in functional evaluation between K-wire technique above and this study. No statistical significance was seen in the distributions of excellent or good cases $(p=0.89 \llbracket 0.05)$.

ESIN is the optimum selection for long bone fractures in children[16]. The advantage of this implant to fix fracture is controlling the fragment far away from the point of implanting nail. For which proximal radius was selected to implant antegrade ESIN. Anatomical study suggested that the distance of supinator entrance of deep radial nerve to lateral epicondyle of humerus was about $1 / 5$ length of the whole forearm (lateral epicondyle of humerus to radial styloid process)[17]. Deep radial nerve went outward obliquely to the back crossing the superficial and deep layers of supinator. So the superior $1 / 3$ point between lateral epicondyle of humerus and radial styloid process was located as implanting plane. $1 \mathrm{~cm}$ was translated palmarly to utilize the muscular interval and to keep away from deep radial nerve in the muscle belly of supinator. In our experience, ESIN reduces fracture by adjusting its tip and fixes the broken ends by penetrating into the distal segment rather than by support of three points. There is no need to insist on anatomical reduction as cancellous bone is major in metaphysis. Compared with crossed K-wires, antegrade ESIN provides more stable fixation and would not injure the tendon, nerve or vessel but another operation to remove the implant is inevitable. 
It is noteworthy that ESIN is merely an effective implant for reduction and fixation which could not instead of manual reduction completely. Large-scale clinical case studies suggested that $93.3 \%$ forearm fractures in children could be treated effectively with cast fixations alone[18]. Thus for children younger than six years, we do not advise them to treat with ESIN radically for good outcomes of casts. For children elder than 14 years or overweight than $50 \mathrm{~kg}$ whose strengths of bones and soft tissues are close to adults and remolding capacities decline, the correction abilities and fixation stabilities of ESIN are inferior relatively. So we do not advocate this technique to be used for them as no deterministic evidence. Opened reduction and plate fixation or hybrid fixation with plate and ESIN should be preferred all the same[19].

In conclusion, antegrade ESIN technique shows great advantage in treating irreducible distal radius fracture in diaphyseal-metaphyseal junction with effective outcomes. This surgical procedure is established basing on the anatomical character of muscular intervals. The site to implant ESIN in proximal radius is a supplement to the minimal invasive operation. The criterion of this approach to implant nail should be studied further.

\section{Declarations}

\section{Compliance with ethical standards}

Conflict of interest The authors declare that they have no conflict of interest.

Ethical approval All procedures performed in studies involving human participants were in accordance with the ethical standards of the institutional and/or national research committee and with the 1964 Helsinki Declaration and its later amendments or comparable ethical standards.

Informed consent No patients were involved. This is a retrospective study of patients' data, and an IRB approval was obtained (LW 2020002).

\section{References}

1. Cai H, Wang Z, Cai H. Prebending of a titanium elastic intramedullary nail in the treatment of distal radius fractures in children. Int Surg. 2014;99(3):269-275. https://doi.org/10.9738/INTSURG-D-1300065.1.

2. Khosla S, Melton LJ 3rd, Dekutoski MB, Achenbach SJ, Oberg AL, et al. Incidence of childhood distal forearm fractures over 30 years: a population-based study. JAMA. 2003;290(11):1479-1485. https://doi.org/10.1001/jama.290.11.1479.

3. Miller BS, Taylor B, Widmann RF, Bae DS, Snyder BD, et al. Cast immobilization versus percutaneous pin fixation of displaced distal radius fractures in children: a prospective, randomized study. $\mathrm{J}$ Pediatr Orthop. 2005;25(4):490-494. https://doi.org/10.1097/01.bpo.0000158780.52849.39. 
4. Huang $\mathrm{W}$, Zhang $X$, Zhu $\mathrm{H}$, Wang $X$, Sun $J$, et al. A percutaneous reduction technique for irreducible and difficult variant of paediatric distal radius and ulna fractures. Injury. 2016;47(6):1229-1235. https://doi.org/10.1016/j.injury.2016.02.011.

5. Cooney WP, Bussey R, Dobyns JH, Linscheid RL. Difficult wrist fractures. Perilunate fracturedislocations of the wrist. Clin Orthop Relat Res. 1987;(214):136-147. https://doi.org/10.1007/BF00456877.

6. Crosby CA, Wehbé MA, Mawr B. Hand strength: normative values. J Hand Surg Am. 1994;19(4):665670. https://doi.org/10.1016/0363-5023(94)90280-1.

7. Johari AN, Sinha M. Remodeling of forearm fractures in children. J Pediatr Orthop B. 1999;8(2):8487. https://doi.org/10.1097/00009957-199904000-00003.

8. Roberts JA. Angulation of the radius in children's fractures. J Bone Joint Surg Br. 1986;68(5):751754. https://doi.org/10.1302/0301-620X.68B5.3782237.

9. Morrey BF, Askew LJ, Chao EY. A biomechanical study of normal functional elbow motion. J Bone Joint Surg Am. 1981;63(6):872-877.

10. Bowman EN, MehIman CT, Lindsell CJ, Tamai J. Nonoperative treatment of both-bone forearm shaft fractures in children: predictors of early radiographic failure. J Pediatr Orthop. 2011;31(1):23-32. https://doi.org/10.1097/BP0.0b013e318203205b.

11. Asadollahi S, Pourali M, Heidari K. Predictive factors for re-displacement in diaphyseal forearm fractures in children-role of radiographic indices. Acta Orthop. 2017;88(1):101-108. https://doi.org/10.1080/17453674.2016.1255784.

12. Kutsikovich JI, Hopkins CM, Gannon EW 3rd, Beaty JH, Warner WC Jr, et al. Factors that predict instability in pediatric diaphyseal both-bone forearm fractures. J Pediatr Orthop B. 2018;27(4):304308. https://doi.org/10.1097/BPB.0000000000000480.

13. Kamat AS, Pierse N, Devane P, Mutimer J, Horne G. Redefining the cast index: the optimum technique to reduce redisplacement in pediatric distal forearm fractures. J Pediatr Orthop. 2012;32(8):787-791. https://doi.org/10.1097/BPO.0b013e318272474d.

14. Pace JL. Pediatric and Adolescent Forearm Fractures: Current Controversies and Treatment Recommendations. J Am Acad Orthop Surg. 2016;24(11):780-788. https://doi.org/10.5435/JAAOSD-15-00151.

15. Lobo-Escolar A, Roche A, Bregante J, Gil-Alvaroba J, Sola A, et al. Delayed union in pediatric forearm fractures. J Pediatr Orthop. 2012;32(1):54-57. https://doi.org/10.1097/BP0.0b013e31823832ea.

16. Barry M, Paterson JM. A flexible intramedullary nails for fractures in children. J Bone Joint Surg Br. 2004;86(7):947-953. https://doi.org/10.1302/0301-620x.86b7.15273.

17. Ozturk A, Kutlu C, Taskara N, Kale AC, Bayraktar B, et al. Anatomic and morphometric study of the arcade of Frohse in cadavers. Surg Radiol Anat. 2005;27(3):171-175. https://doi.org/10.1007/s00276-005-0321-z.

18. Baldwin K, Morrison MJ 3rd, Tomlinson LA, Ramirez R, Flynn JM. Both bone forearm fractures in children and adolescents, which fixation strategy is superior - plates or nails? A systematic review 
and meta-analysis of observational studies. J Orthop Trauma. 2014;28(1):e8-8e14.

https://doi.org/10.1097/BOT.0b013e31829203ea.

19. Zheng W, Tao Z, Chen C, Zhang C, Zhang H, et al. Comparison of three surgical fixation methods for dual-bone forearm fractures in older children: A retrospective cohort study. Int J Surg. 2018;51:10-16. https://doi.org/10.1016/j.ijsu.2018.01.005.

\section{Tables}

Table. 1 Comparisons of ROM of bilateral wrists $\left(n=27,{ }^{\circ}\right)$

\begin{tabular}{|lllll|}
\hline ROM & Involved side & Healthy side & $\mathrm{t}$ & $\mathrm{p}$ \\
\hline Palmar flexion & $80 \pm 5(66-87)$ & $79 \pm 4(71-86)$ & 0.467 & 0.644 \\
\hline Dorsal extension & $70 \pm 5(60-80)$ & $72 \pm 5(62-82)$ & -1.187 & 0.246 \\
\hline Flexion-extension & $150 \pm 6(141-167)$ & $151 \pm 6(144-167)$ & -0.747 & 0.462 \\
\hline Radial inclination & $15 \pm 2(10-20)$ & $17 \pm 2(12-22)$ & -2.013 & 0.055 \\
\hline Ulnar inclination & $37 \pm 4(30-46)$ & $36 \pm 3(30-44)$ & 0.883 & 0.386 \\
\hline Supination & $87 \pm 4(81-99)$ & $86 \pm 6(75-95)$ & 0.466 & 0.645 \\
\hline Pronation & $76 \pm 6(65-86)$ & $79 \pm 6(68-90)$ & -1.310 & 0.202 \\
\hline
\end{tabular}

Table.2 Cooney modified Green and O'Brien score and grade $(\mathrm{n}=27)$

\begin{tabular}{|ll|}
\hline Item & Score \\
\hline Total score & $93 \pm 6(80-100)$ \\
\hline Pain & $25 \pm 0(25-25)$ \\
\hline Function & $25 \pm 0(25-25)$ \\
\hline ROM & $22 \pm 5(15-25)$ \\
\hline Grip strength & $22 \pm 5(15-25)$ \\
\hline Grade & \\
\hline Excellent & $93 \%(n=25)$ \\
\hline Good & $7 \%(n=2)$ \\
\hline Moderate & - \\
\hline Poor & - \\
\hline
\end{tabular}


Cooney[5]

\section{Figures}

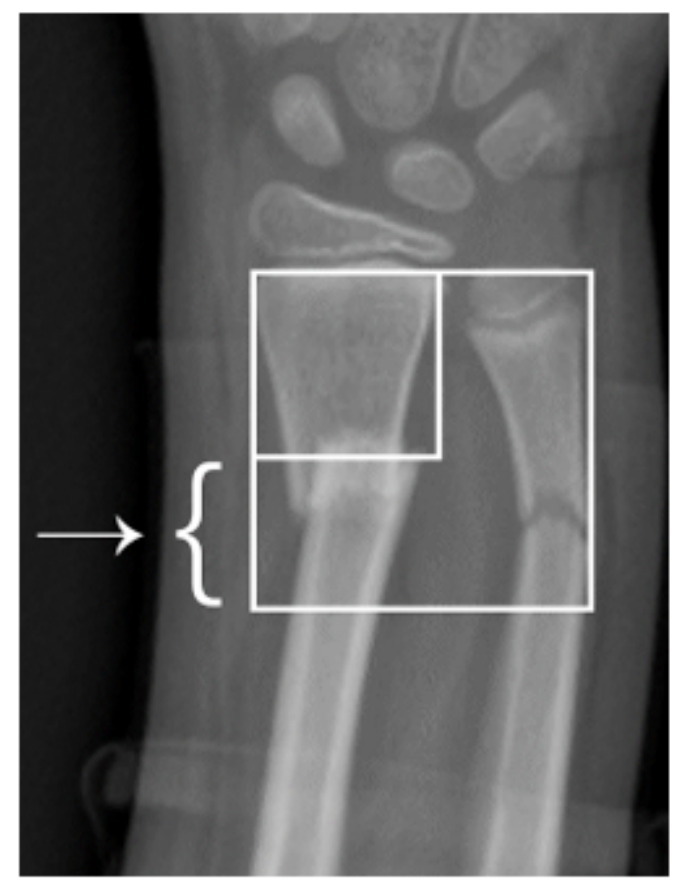

\section{Figure 1}

The arrow indicates the site of distal radius fracture in children where the junction of diaphysealmetaphyseal of radius locates

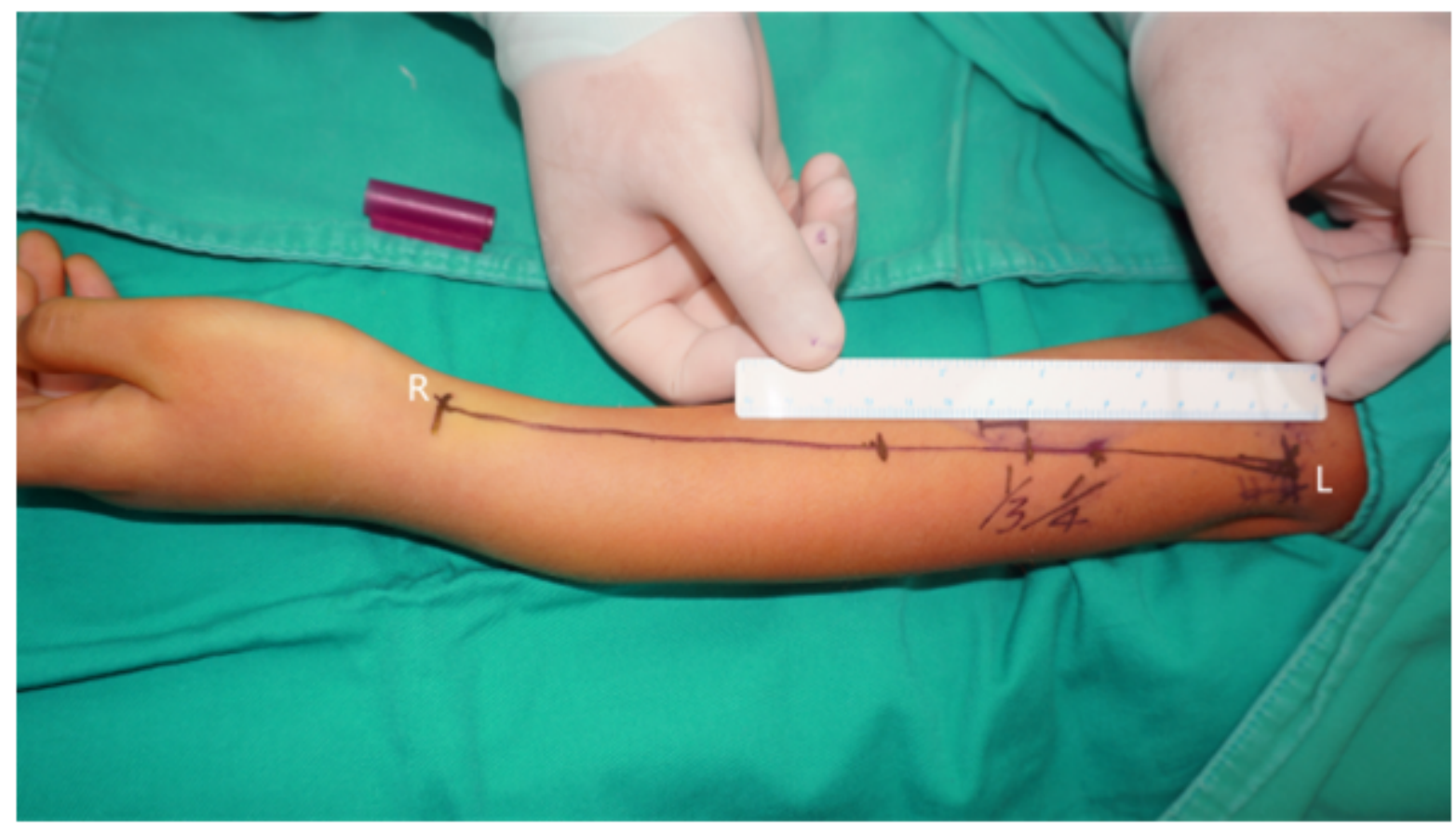


Figure 2

The incision located about $1 \mathrm{~cm}$ palmarly to the superior $1 / 3$ point between lateral epicondyle of humerus $(\mathrm{L})$ and radial styloid process $(\mathrm{R})$
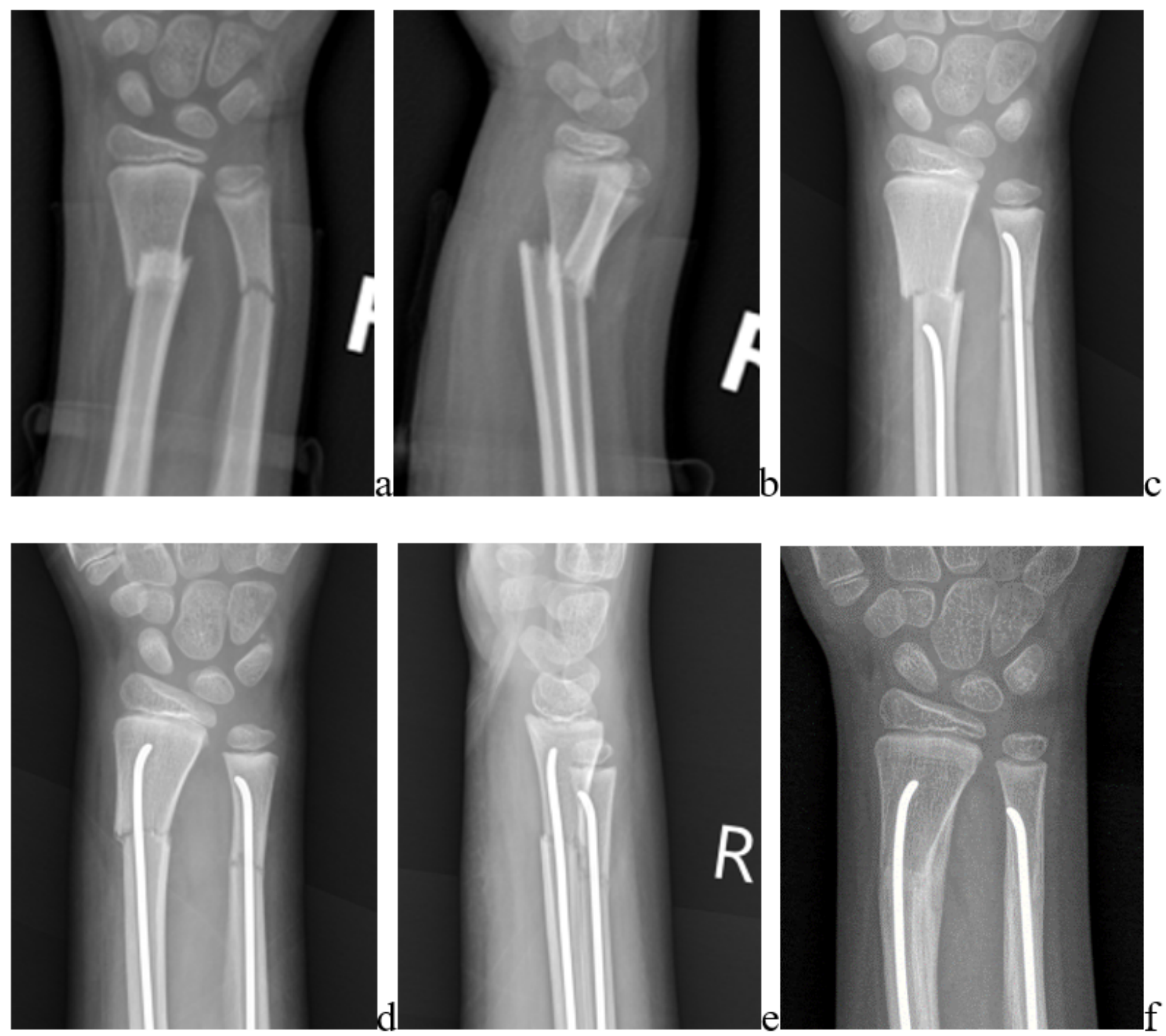

\section{Figure 3}

An eight years boy with irreducible distal radius and ulnar fracture in his right forearm $(a, b)$. The ulnar fracture was reduced and fixed firstly then the radius broken ends were reduced partly in order to penetrate the nail (c). The nail was beat into the distal end and its tip was adjust towards the ulnar side $(d, e)$. Four months later, the fractures healed and remodelled well (f) 


\section{Supplementary Files}

This is a list of supplementary files associated with this preprint. Click to download.

- AntegradeTEN.xIsx 